\title{
Sucrose Metabolism in Ripening Muskmelon Fruit as Affected by Leaf Area
}

\author{
Natalie L. Hubbard and D. Mason Pharr \\ Department of Horticultural Science and Plant Physiology Program, North Carolina State \\ University, Raleigh, NC 27695-7609
}

\author{
Steven C. Huber \\ U.S. Department of Agriculture, Agricultural Research Service, Departments of Crop Science and \\ Botany, and Plant Physiology Program, Raleigh, NC 27695
}

Additional index words. Cucumis melo, sucrose phosphate synthase, acid invertase, sink metabolism

\begin{abstract}
Muskmelon (Cucumis melo L.) fruit lack a stored starch reserve and therefore depend on translocated photoassimilate from the leaf canopy for sugar accumulation during ripening. The influence of canopy photosynthesis on sucrose' accumulation within muskmelon fruit mesocarp was examined. Canopy photosynthetic activities were estimated in a sweet and a nonsweet genotype. Photosynthetic rate of the nonsweet genotype, on a per-plant basis, was only $56 \%$ of that of the sweet genotype. The effect of limiting leaf area of the sweet genotype on carbohydrate concentrations and sucrose metabolizing enzymes within the fruit was evaluated. A 50\% reduction of leaf area 8 days before initiation of fruit sucrose accumulation resulted in canopy photosynthesis similar to that of the nonsweet genotype. Reduced photosynthetic activity resulted in slightly lower soluble-carbohydrate concentration in the fruit; however, fruit sucrose concentration was three times higher than that reported previously for the nonsweet genotype. The extent to which 'fruit sucrose phosphate synthase (SPS) activity increased during maturation was diminished by leaf removal. Acid invertase activity declined in all fruit in a similar manner irrespective of defoliation. A reduction of leaf area of a sweet genotype reduced sucrose accumulation within the fruit. Lower fruit sucrose concentration was associated with lower concentration of raffinose saccharides and lower SPS activity within the fruit. Additionally, insufficient assimilate supply was judged not to be the factor responsible for low sucrose accumulation in a nonsweet genotype.
\end{abstract}

Sucrose concentration of muskmelon mesocarp is a major component of fruit quality. Sucrose accumulation is one of several processes generally associated with ripening that commence midway through fruit development and continue until maturity (Pratt, 1971).

Hubbard et al. (1989) recently reported that most, if not all, of the sucrose accumulating in muskmelon fruit as they ripen on the plant is synthesized within the fruit by the enzyme sucrose phosphate synthase (SPS) (EC 2.4.1.14). In contrast to other reports of very low SPS activity in muskmelon fruit (Lingle and Dunlap, 1987), Hubbard et al. (1989) found SPS activity as high as $38 \mu \mathrm{mol} \cdot \mathrm{hr}^{-1} \cdot \mathrm{g}^{-1}$ (fresh weight) in mature muskmelon mesocarp. Moreover, fruit SPS activity increased during development as sucrose concentration increased. Lower SPS activity in fruit of a nonsweet muskmelon genotype, as compared to a sweet genotype, provided additional evidence for control of sucrose synthesis by this enzyme within the fruit (Hubbard et al., 1989).

There is increasing evidence that the concomitant decline in acid invertase activity and increase in SPS activity within the muskmelon fruit are necessary for an increase in fruit sucrose concentration during ripening (Hubbard et al., 1989). Lack of sucrose accumulation early in muskmelon fruit development,

Received for publication 29 Jan. 1990. Cooperative investigation of the North Carolina Agricultural Research Service, U.S. Dept. of Agriculture, and Agricultural Research Service, Raleigh, N.C. This work was supported in part by BARD grant no. 1-1062-86. Paper no. 12533 of the Journal Series of the North Carolina Agricultural Research Service, Raleigh, NC 27695-7643. Mention of a trademark or proprietary product does not constitute a guarantee or warranty of the product by the North Carolina Agricultural Research Service or the U.S. Dept. of Agriculture and does not imply its approval to the exclusion of other products that may also be suitable. We thank Sharon Funderburk for expert technical assistance. The cost of publishing this paper was defrayed in part by the payment of page charges. Under postal regulations, this paper therefore must be hereby marked advertisement solely to indicate this fact. despite the presence of SPS activity, is apparently due to rapid sucrose degradation (Hubbard et al., 1989). Activities of sucrose synthase (EC 2.4.1.13) and neutral invertase (EC 3.2.1.26) were relatively low throughout development (Hubbard et al., 1989; Lingle and Dunlap, 1987; McCollum et al., 1988; Schaffer et al., 1987). Acid invertase activity was high early in development and declined as the fruit matured (Hubbard et al., 1989; Lingle and Dunlap, 1987; McCollum et al., 1988; Schaffer et al., 1987).

The fruit represents a major sink that depends on translocated carbohydrates from the leaf canopy. Muskmelon fruit do not have a stored starch reserve (Pratt, 1971) as do apples (Hulme and Rhodes, 1971), bananas (Palmer, 1971), and other fruits that can sweeten from starch degradation in a postharvest environment (Whiting, 1970). Therefore, muskmelons require a concurrent supply of photoassimilates from leaves for sugar accumulation during ripening. The objective of this study was to determine the effect of reduced canopy photosynthesis on subsequent carbohydrate concentrations and activities of sucrosemetabolizing enzymes within muskmelon fruit.

\section{Materials and Methods}

Plant material. Two green-fleshed muskmelon genotypes known to differ in soluble sugar concentration within the fruit at maturity were used. Reports of total soluble sugar concentrations at maturity of the sweet genotype, 'Noy Yizreel', ranged from $\approx 160$ to $90 \mathrm{mg} \cdot \mathrm{g}^{-1}$ (fresh weight), while those of the nonsweet genotype, 'Birds Nest', ranged from $\approx 25$ to $50 \mathrm{mg} \cdot \mathrm{g}$ (fresh weight). Between $44 \%$ and $63 \%$ of the soluble sugar pool was sucrose in 'Noy Yizreel' while <20\% of the soluble sugar pool was sucrose in 'Birds Nest' (Hubbard et al., 1989; Schaffer

Abbreviations: CER, net carbon exchange rate; DAA, days after an thesis; SPS, sucrose phosphate synthase. 
et al., 1987). 'Noy Yizreel' and 'Birds Nest' plants were grown in a greenhouse from Oct. through Dec. 1988. A second crop of 'Noy Yizreel' was grown from Mar. through June 1989.

Plants were grown in a mixture of 1 steam-treated soil : 1 sand : 1 peat (by volume) in 5.9-liter pots. Plants were trained to two laterals, trellised, and fertilized weekly with soluble fertilizer (10N-4.3 P-8.3 K). Flowers were hand-pollinated and tagged. Fruit load was limited to one fruit per plant.

Treatments were $0 \%$ (control), 50\%, and $100 \%$ removal of leaves (leaf blade plus petiole) from 'Noy Yizreel' plants. In both experiments, treatments were imposed 24 DAA. The leaf at the fruiting node remained on the lateral in the 50\% leaf removal treatment, with every other leaf excised at the base of the petiole. The second experiment included a fourth treatment in which fruit were detached from the lateral and supported in place using a plastic mesh bag.

" There were four replications (individual fruit) in the first experiment. Fruit were harvested $37 \pm 2$ DAA. The second experiment had four replications for sampling 24 and 28 DAA. Analysis of early samples indicated that the fruit had not begun to accumulate sucrose; therefore, the sampling period was extended to $52 \mathrm{DAA}$ with two replications per sampling. Fruit were harvested every 4 days from 24 through 52 DAA. Detached fruit were sampled 32, 36, 40, and 44 DAA.

Fruit mesocarp tissue was sampled, frozen in liquid $\mathrm{N}_{2}$, and stored at $-80 \mathrm{C}$ as described by Hubbard et al. (1989). A portion of fruit mesocarp tissue was weighed at sampling and dried in a forced-air oven at 70C until a constant weight was obtained to determine dry weight percentage.

Although fruit mesocarp was divided into inner and outer mesocarp segments at sampling, trends observed between the two tissue positions were similar to those reported previously (Hubbard et al., 1989). Therefore, all data are presented as the mean of the two mesocarp subsamples.

Carbon exchange rate. CER was measured in a closed system using a LI-COR Model 6000 Portable Photosynthesis Meter (LICOR, Lincoln, Neb.). CER measurements were made on the leaf at the fruiting node and the corresponding leaf on the nonfruiting lateral 1 day before leaf removal in the first experiment.

CER measurements were made 25 and 26 DAA on control plants to determine differences in photosynthetic activity within the plant canopy between the two genotypes. Measurements were taken on the leaf basipetal to the fruiting node, the leaf of the fruiting node, and every third leaf acropetal to the fruit .CER measurements were also made at comparable leaf positions on the laterals not bearing fruits.

To determine the effect of the $50 \%$ leaf removal treatment on CER of remaining leaves, measurements were made on several leaves of control plants and those with $50 \%$ of their leaves removed. CER measurements were made on the leaf at the fruiting node and the seventh leaf acropetal to the fruit 1 day before leaf removal and 2, 7, and 12 days after leaf removal.

Extraction and analysis of soluble carbohydrates. A subsample from each sample was weighed, ground in 3 to $5 \mathrm{ml} 80 \%$ ethanol, and placed in an $80 \mathrm{C}$ water bath for $5 \mathrm{~min}$. After cooling, the samples were centrifuged and supernatants were collected. Ethanolic extraction was repeated two additional times. Supernatants were combined and brought to $15 \mathrm{ml}$ volume with $80 \%$ ethanol. A 3-ml aliquot from each sample was evaporated to dryness in vacuo with a Buchler Evapo-Mix (Buchler Instruments, Fort Lee, N.J.). Samples were resolubilized in $1 \mathrm{ml}$ water for use in soluble-sugar analyses.

High performance liquid chromatography was used to mea- sure stachyose and raffinose in extracts from fruit sampled at 24 and 44 DAA from each treatment. The high performance liquid chromatography system was comprised of a Waters 6000A pump (Millipore, Waters Chromatography Div., Milford, Mass.) that delivered the solvent (water) at a rate of $0.5 \mathrm{ml} \cdot \mathrm{min}^{-1}$. The column, a Waters Sugar Pak I, was maintained at 75C and was preceded by microguard anion and cation exchange guards (Bio Rad, Richmond, Calif.) held at 22C. A Waters 401 refractive index detector and Spectra-Physics SP4200 computing integrator (Spectra-Physics, San Jose, Calif.) were used for sugar detection and recording of retention times and peak areas. Sample size was $20 \mu \mathrm{l}$. Sugars were identified and quantified from retention times and peak areas of known standards.

Sucrose and hexose sugar concentrations were determined enzymatically. For hexose analysis, an aliquot of extract was incubated in a solution $(1 \mathrm{ml})$ containing $100 \mathrm{~mm} \mathrm{Hepes}-\mathrm{NaOH}$ (pH 8.0), 5 mM $\mathrm{MgCl}_{2}, 1$ mM NAD, 1 mMATP, 5 mм DTT, 2.5 units hexokinase (EC 2.7.1.1), 2.5 units glucose-6-P dehydrogenase (EC 1.1.1.49) (prepared from Leuconostoc mesenteroides), and two units phosphoglucoisomerase (EC 5.3. 1.9). The same reaction mixture was used for sucrose analysis with the addition of 16 units yeast invertase (EC 3.2.1.26). Absorbance at $340 \mathrm{~nm}$ was measured spectrophotometrically after 30 min at 25C. Sugar concentrations were determined by comparison with hexose and sucrose standards.

Enzyme extraction and assays. Enzyme extraction and assays for SPS, acid and neutral invertases, and sucrose synthase activities were conducted as described by Hubbard et al. (1989).

\section{Results}

Genotypic differences in CER. The nonsweet genotype 'Birds Nest' had lower photosynthetic activity (per unit leaf area) throughout the canopy than the sweet genotype 'Noy Yizreel' (Fig. 1) and its mean CER was about one-third that of the latter (Table 1). CER increased as a function of distance from the fruit until node five in both 'Noy Yizreel' and 'Birds Nest' plants. The fruit were near the base of the plant; thus, lower

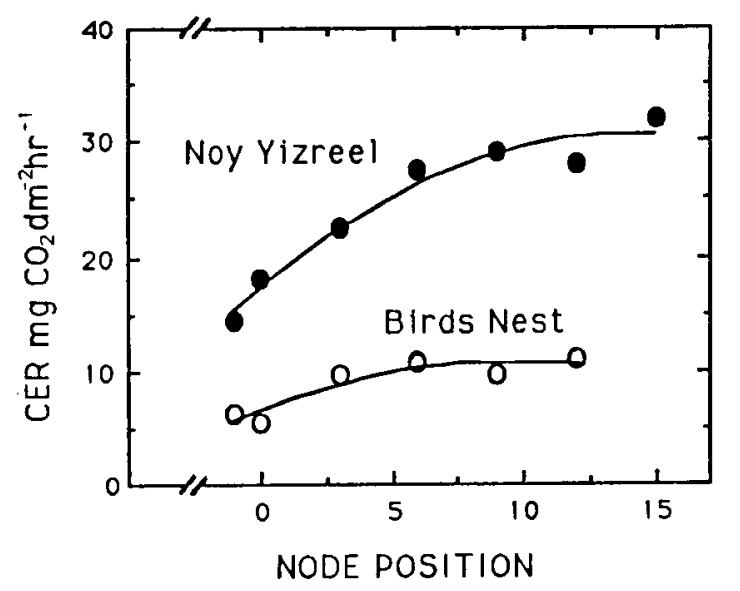

Fig. 1. Net CER of sweet ( $\bigcirc$ 'Noy Yizreel') and nonsweet ( $\bigcirc$ 'Birds Nest') muskmelon genotypes. Measurements were taken from leaves one node position basipetal to the fruit, the node at which the fruit was located, and every third leaf acropetal to the fruit to leaves 12 and 15. Leaves at comparable positions on the nonfruiting laterals were measured. Node position $\mathrm{O}$ on the graph corresponds to the position of the fruit. Data points for each genotype are the mean of two plants, fruiting and nonfruiting laterals. Measurements were made 25 and 26 DAA. 
CERS of leaves near the fruit may reflect a loss of photosynthetic activity as leaves age.

Total leaf area of 'Birds Nest' canopy was greater than that of 'Noy Yizreel'. Despite this, on a per-plant basis, CER of 'Birds Nest' was only $\approx 56 \%$ as great as that of 'Noy Yizreel' (Table 1).

Removal of $50 \%$ of the leaves from 'Noy Yizreel' plants did not result in an increase in CER of the remaining leaves (Fig. 2 ). These data document that a $50 \%$ reduction of leaf area of 'Noy Yizreel' limited canopy photosynthesis and, thus, total canopy photoassimilate production rate to levels similar to the nonsweet genotype 'Birds Nest'.

Effect of defoliation on fruit carbohydrates. Fruit from the first experiment were harvested before the period of sucrose accumulation. Concentrations of hexose sugars and raffinose saccharides declined with increasing levels of defoliation (Table 2 ). However, the lack of substantial amounts of sucrose in any fruit sampled made it impossible to ascertain the effects of leaf removal on fruit sucrose metabolism.

The harvest period was extended to 52 DAA in the second experiment to ensure that sampling took place well into the sucrose accumulation period. Sucrose accumulation began in the fruit of $0 \%$ and $50 \%$ leaf removal treatments 8 to 10 days after leaf removal and continued until the final harvest (Fig. 3A). Final sucrose concentrations in fruit of 'Noy Yizreel' plants with $50 \%$ and $100 \%$ of the leaves removed were $\approx 78 \%$ and $26 \%$ of the control $(0 \%)$ plants, respectively. Complete defoliation resulted in fruit sucrose concentrations of $<15 \mathrm{mg} \cdot \mathrm{g}^{-1}$

Table 1. Mean CER of leaves within the leaf canopy, total leaf area per plant, and calculated CER per plant canopy of nonsweet 'Birds Nest' and sweet 'Noy Yizreel' muskmelon genotypes.

$\left.\begin{array}{lccc}\hline \hline & \begin{array}{c}\text { Mean leaf } \\ \mathrm{CER}^{z} \text { (mg }\end{array} & \begin{array}{c}\text { Total leaf } \\ \text { area } \\ \left(\mathrm{dm}^{2} / \text { plant }\right)\end{array} & \begin{array}{c}\text { CER/plant } \\ (\mathrm{mg} \mathrm{CO} / \text { plant } \\ \text { per hr })\end{array} \\ \hline \text { Benotype } & \mathrm{CO}_{2} / \mathrm{dm}^{2} \text { per hr) }\end{array}\right)$

${ }^{2}$ Mean CER of leaves within -the plant canopy. CER measurements were made on the leaf basipetal to the fruiting node, the leaf of the fruiting node, and every third leaf acropetal to the fruit. CER was measured at comparable leaf positions on the nonfruiting lateral. Measurements were made on four plants.

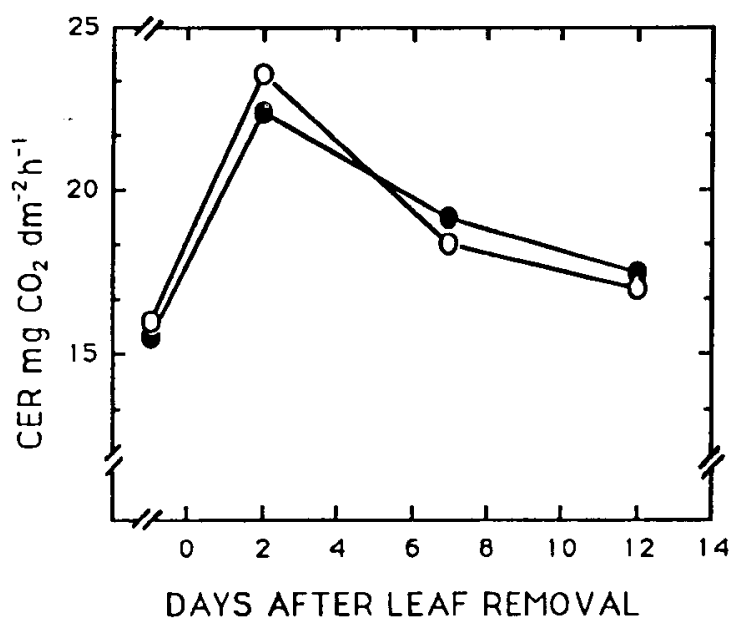

Fig. 2. Net CER of 'Noy Yizreel' control plants ( $($ ) and plants with $50 \%$ of the leaves removed ( $\bigcirc$ ). Measurements were taken 1 day before leaf removal and 2, 7, and 12 days after leaf removal. Data points are the mean of four plants, fruiting and nonfruiting laterals.
Table 2. Concentration of raffinose saccharides, hexose sugars, and sucrose in 'Noy Yizreel' muskmelon fruit mesocarp at 37 DAA as influenced by leaf removal.

\begin{tabular}{lccr}
\hline \hline $\begin{array}{c}\text { Leaves removed } \\
(\%)\end{array}$ & $\begin{array}{c}\text { Raffinose } \\
\text { saccharides }\end{array}$ & Hexoses & Sucrose \\
\hline & $\mu g \cdot g^{-1}$ (fresh weight) & $m g \cdot g^{-1}$ & (fresh $w t)$ \\
0 (Control) & $128.0^{\mathrm{z}} \mathrm{a}^{\mathrm{y}}$ & $49.8 \mathrm{a}$ & $4.9 \mathrm{a}$ \\
50 & $91.6 \mathrm{ab}$ & $36.0 \mathrm{~b}$ & $4.2 \mathrm{a}$ \\
100 & $45.1 \mathrm{~b}$ & $31.7 \mathrm{~b}$ & $2.0 \mathrm{a}$ \\
\hline
\end{tabular}

${ }^{2}$ Data are the mean of four fruit, inner and outer tissues.

'Means within a column followed by the same letter are not significantly different at $P=0.05$ based upon analysis of variance and least significant difference test.

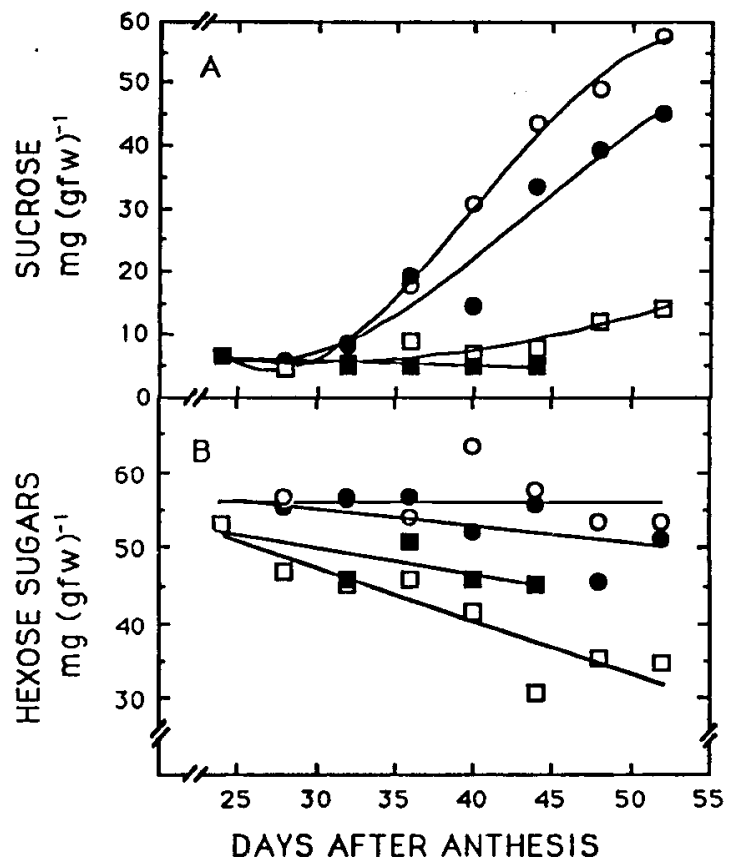

Fig. 3. Sucrose (A) and hexose (B) concentrations of 'Noy Yizreel' fruit mesocarp from 24 to 52 DAA for plants with $(\bigcirc) 0 \%$, ( $O$ ) $50 \%$, or (D) $100 \%$ of leaves removed, and for ( $)$ detached fruit. Regression equations for sucrose concentration were as follows: For $0 \%, \mathrm{y}=286.61-25.06 \mathrm{x}+0.70 \mathrm{x}^{2}-0.006 \mathrm{x}^{3} R^{2}=0.996$; for $50 \%, \mathrm{y}=129.03-10.84 \mathrm{x}+0.29 \mathrm{x}^{2}-0.002 \mathrm{x}^{3}, R^{2}=0.949$; for $100 \%, \mathrm{y}=19.20-0.94 \mathrm{x}+0.016 \mathrm{x}^{2}, R^{\prime}=0.869$; for detached fruit, $\mathrm{y}=8.14-0.08 \mathrm{x}, R^{2}=0.861$. Regression equations for hexose concentration were as follows: For $0 \%, y=56.16-$ $0.005 \mathrm{x}, R^{2}=0.00 ;$ for $50 \%, \mathrm{y}=61.41-0.22 \mathrm{x}, R^{2}=0.311$; for $100 \%, \mathrm{y}=68.19-0.70 \mathrm{x}, R^{2}=0.831$; for detached fruit, $\mathrm{y}$ $=60.39-0.35 \mathrm{x}, R^{2}=0.556$.

(fresh weight), which is similar to the sucrose concentration of mature 'Birds Nest' fruit (Hubbard et al., 1989). Detached fruit accumulated no sucrose during the sampling period.

Hexose sugars were present in high concentrations in fruit of each treatment (Fig. 3B). The hexose sugar pools remained relatively constant, except in the case of fruit from plants with $100 \%$ of the leaves removed. With no leaves remaining on the plant, fruit hexose declined from 50 to $35 \mathrm{mg} \cdot \mathrm{g}^{-1}$ (fresh weight) during the sampling period. The equivalent decline in hexose sugar and increase in sucrose suggested that the hexose pool provided substrate for sucrose synthesis within these fruit.

Dry weight percentage of fruit mesocarp in the $0 \%$ and $50 \%$ leaf removal treatments increased from $6 \%$ to $10 \%$ (Fig. 4). The change in dry weight percentage could be accounted for by the 


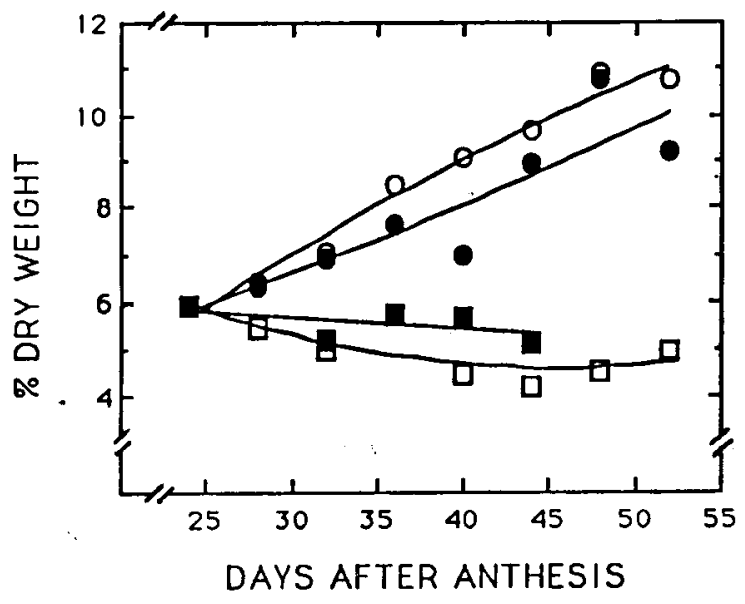

Fig. 4. Percentage dry weight of 'Noy Yizreel' fruit mesocarp from 24 to 52 DAA for plants with ( $\bigcirc$ ) $0 \%$, ( ○ ) $50 \%$, or $\square$ ) $100 \%$ of leaves removed, and for $(\boldsymbol{\square})$ detached fruit. Regression equations were as follows: For $0 \%, \mathrm{y}=-0.85+0.31 \mathrm{x}-0.002 \mathrm{x}^{2}, R^{2}=$ 0.977 ; for $50 \%, \mathrm{y}=3.35+0.08 \mathrm{x}+0.001 \mathrm{x}^{2}, R^{2}=0.794$; for $100 \%, \mathrm{y}=10.53-0.26 \mathrm{x}+0.003 \mathrm{x}^{2}, R^{2}=0.619$; detached fruit, $\mathrm{y}=6.38-0.02 \mathrm{x}, R^{2}=0.308$.

increase in sucrose in these fruit. There was no net accumulation of solids in fruit on vines with $100 \%$ of leaves removed or in detached fruit.

Effect of defoliation on enzyme activities. Of the sucrose metabolizing enzymes, SPS activity was most affected by the leaf and fruit removal treatments. In fruit of control plants, SPS activity rose to a distinct peak and then declined (Fig. 5A). SPS activity in fruit of these plants increased from $22 \mu \mathrm{mol} \cdot \mathrm{hr}^{-1} \cdot \mathrm{g}^{-1}$ (fresh weight) at $24 \mathrm{DAA}$ to $38 \mu \mathrm{mol} \cdot \mathrm{hr}^{-1} \cdot \mathrm{g}^{-1}$ (fresh weight) at 36 DAA, after which activity declined. SPS activity in fruit of the $50 \%$ leaf removal treatment increased to $\approx 30$ $\mu \mathrm{mol} \cdot \mathrm{hr}^{-1} \cdot \mathrm{g}^{-1}$ (fresh weight) and then began to decrease at 40 DAA. In fruit of the $100 \%$ leaf removal treatment, SPS activity remained constant until 32 DAA, after which time it decreased. SPS activity in detached fruit declined soon after the treatment was imposed.

Acid invertase activity decreased from $12 \mu \mathrm{mol} \cdot \mathrm{hr}^{-1} \cdot \mathrm{g}^{-1}$ (fresh weight) to $<2 \mu \mathrm{mol} \cdot \mathrm{hr}^{-1} \cdot \mathrm{g}^{-1}$ (fresh weight) in all fruit that remained attached to the plant (Fig. 5B). Detached fruit were sampled only to 44 DAA, by which time acid invertase activity had declined to $5 \mu \mathrm{mol} \cdot \mathrm{hr}^{-1} \cdot \mathrm{g}^{-1}$ (fresh weight).

Sucrose synthase activity was low and remained constant in fruits of the treated plants during the sampling period. However, in fruit of control plants, sucrose synthase activity increased (Fig. 6A). Neutral invertase activity was low and did not change in the $0 \%$ and $50 \%$ leaf removal treatments (Fig. 6B). Activity of neutral invertase declined in the $100 \%$ leaf removal and detached fruit treatments, but activity overall was low, and in absolute terms the decline was small.

\section{Discussion}

Canopy photosynthetic activity of the sweet muskmelon genotype 'Noy Yizreel' was higher than that of the nonsweet genotype 'Birds Nest' by almost 2-fold. When leaf area was reduced by $50 \%$, 'Noy Yizreel' had a canopy photosynthetic activity equivalent to that of 'Birds Nest'. Thus, photosynthate supply of the sweet and nonsweet genotypes was similar during the period of sucrose accumulation. However, sucrose concentration of fruit from sweet genotype plants with $50 \%$ of the

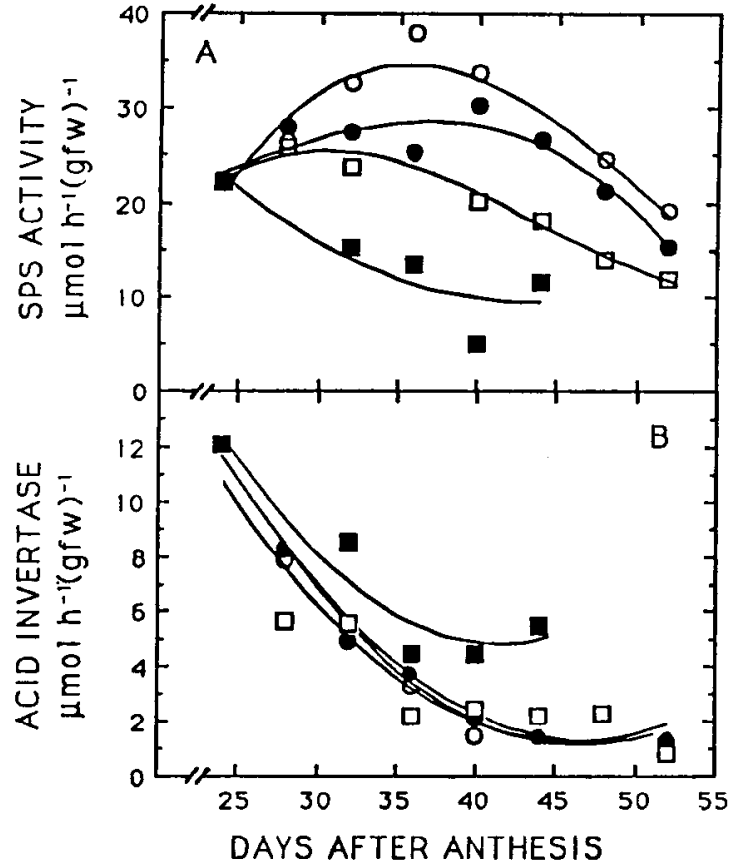

Fig. 5. SPS (A) and acid invertase (B) activities of 'Noy Yizreel' fruit mesocarp from 24 to 52 DAA for plants with $(\bigcirc) 0 \%,(\bullet)$ $50 \%$, or (], $100 \%$ leaves removed, and for ( $\mathbf{0})$ detached fruit. Regression equations for SPS activity were as follows: for $0 \%, \mathrm{y}=$ $-145.06+12.14 \mathrm{x}-0.26 \mathrm{x}^{2}+0.002 \mathrm{x}^{3}, R^{2}=0.897$; for $50 \%$, $\mathrm{y}=13.25-0.42 \mathrm{x}+0.057 \mathrm{x}^{2}-0.001 \mathrm{x}^{3}, R^{2}=0.871$; for $100 \%$, $\mathrm{y}=-82.97+8.69 \mathrm{x}-0.22 \mathrm{x}^{2}+0.002 \mathrm{x}^{3}, R^{2}=0.967$; for detached fruit, $\mathrm{y}=78.90-3.12 \mathrm{x}+0.036 \mathrm{x}^{2}, R^{2}=0.785$. Regression equations for acid invertase activity were as follows: For $0 \%, \mathrm{y}=47.37-2.00 \mathrm{x}+0.022 \mathrm{x}^{2}, R^{2}=0.985 ;$ for $50 \%, \mathrm{y}=$ $44.00-1.80 \mathrm{x}+0.019 \mathrm{x}^{2}, R^{2}=0.986$; for $100 \%, \mathrm{y}=42.27-$ $1.78 \mathrm{x}+0.019 \mathrm{x}^{2}, R^{2}=0.889$; for detached fruit, $\mathrm{y}=47.30-$ $2.04 \mathrm{x}+0.025 \mathrm{x}^{2}, R^{2}=0.910$

leaves removed was three times that of the nonsweet genotype as reported previously (Hubbard et al., 1989; Schaffer et al., 1987). Within the limits of these observations, lower photoassimilate availability does not appear to account for low fruit sucrose concentration in fruit of the nonsweet genotype.

Fruit sucrose accumulation occurred later in fruit development and final sucrose concentration was greater at maturity than in previous studies of the same genotype (Hubbard et al., 1989; McCollum et al., 1988). The time required for maturation of 'Noy Yizreel' fruit appears to be influenced by environmental factors (McCollum et al., 1987). Welles and Buitelaar (1988) reported that an increase in maturation period of muskmelon fruit was associated with higher soluble solids content. In their study, prolonged ripening resulted from low night temperatures and high leaf area. The longer period required for maturation in this study may have been a result of daylength, temperature, or some other environmental factor(s) including those resulting from trellising the plants.

Slow ripening and, therefore, a longer fruit sampling period revealed a pattern of SPS activity in muskmelon fruit previously unreported (Fig. 5A). SPS activity in control fruit increased as reported previously (Hubbard et al., 1989), but after reaching a peak at 36 DAA, activity declined. Despite the decline in fruit SPS activity, sucrose accumulation continued until final harvest in fruit of control plants and plants with $50 \%$ of the leaves removed (Fig. 3A). During that interval, SPS activity remained higher than the sum of the activities of all the sucrose-degrading 


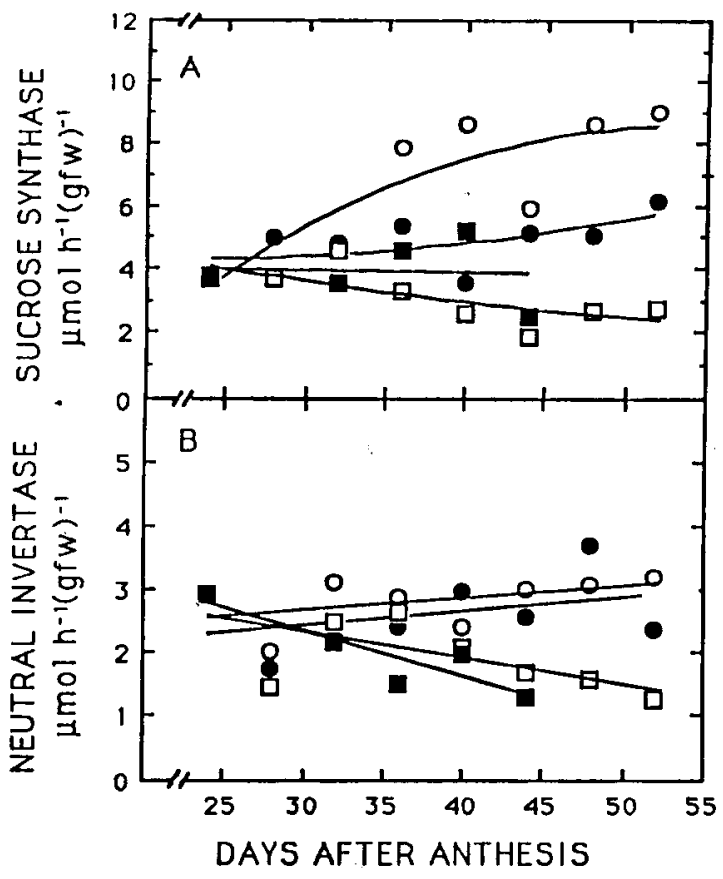

Fig. 6. Sucrose synthase (A) and neutral invertase (B) activities of 'Noy Yizreel' fruit mesocarp from 24 to 52 DAA for plants with ( $\bigcirc)$ ) $0 \%,(\bigcirc) 50 \%, \square) 100 \%$ leaves removed and for $(\mathrm{H})$ detached fruit. Regression equations for sucrose synthase activity were as follows: For $0 \%, \mathrm{y}=-8.08+0.62 \mathrm{x}-0.006 \mathrm{x}^{2}, R^{2}=0.751$; for $50 \%, \mathrm{y}=5.12-0.07 \mathrm{x}+0.002 \mathrm{x}^{2}, R^{2}=0.350$; for $100 \%$, $\mathrm{y}=6.64-0.13 \mathrm{x}+0.001 \mathrm{x}^{2}, R^{2}=0.522$; for detached fruit, $\mathrm{y}$ $=4.14-0.007 \mathrm{x}, R^{2}=0.003$. Regression equations for neutral invertase activity were as follows: For $0 \%, \mathrm{y}=2.07+0.019 \mathrm{x}$, $R^{2}=0.221$; for $50 \%, \mathrm{y}=1.74+0.023 \mathrm{x}, R^{2}=0.142$; for $100 \%$, $\mathrm{y}=3.59-0.042 \mathrm{x}, R^{2}=0.444$; detached fruit, $\mathrm{y}=4.50-$ $0.072 \mathrm{x}, R^{2}=0.797$.

enzymes, acid and neutral invertases, and sucrose synthase. This result is consistent with the previously reported conclusion that the enzymatic capacity for sucrose synthesis in the fruit must exceed the capacity for sucrose degradation before sucrose accumulation can occur (Hubbard et al., 1989).

Sucrose synthase activity doubled in fruit of control plants during the sampling period (Fig. 6A). Others (McCollum et al., 1988; Schaffer et al., 1987) have suggested that a small increase in sucrose synthase activity during fruit development was associated with sucrose accumulation. However, this is the first of several studies in which we have detected any increase in sucrose synthase activity. Because of the relatively low activities reported, the variation among studies with regard to changes during development, and the probable role of the enzyme in sucrose degradation, the small increase in sucrose synthase activity in control fruit in this study is not viewed as important in sucrose synthesis associated with sweetening.

The extent to which fruit SPS activity increased after 24 DAA was affected by leaf removal. The greater the reduction in canopy photosynthetic capacity, the lower the fruit SPS activity (Fig. 5A). While the mechanisms are not understood, we conclude that developmental changes in enzyme activities within the muskmelon fruit can be modulated in response to translocated substances from the source tissues. Detachment of fruit and, presumably, defoliation limited the import of photosyn- thate and possibly other substances, such as growth regulators, to the fruit.

A drastic reduction of translocate from the source, by detaching fruit or complete defoliation, severely reduced sucrose accumulation in the fruit (Fig. 3A) despite the presence of the enzymatic capacity for net sucrose synthesis within the fruit (Fig. 4A). The inability to accumulate sucrose is presumably due, in part, to decreased import of the raffinose saccharides, which are the predominant translocated forms of carbohydrate in Cucumis (Zimmerman and Ziegler, 1975). Fruit from completely defoliated plants synthesized small quantities of sucrose, apparently at the expense of the endogenous hexose pool (Fig. 3 A and B). Lester and Dunlap (1985) reported a similar phenomenon in mature muskmelon fruit after 10 days of storage. A continued supply of assimilates is clearly necessary for sucrose synthesis and accumulation to occur. This implies that fruit such as muskmelon that do not have a major storage carbohydrate such as starch must be maintained on the plant until maturity to ensure adequate quality, as has been reported (Bianco and Pratt, 1977; Pratt, 1971). Also, environmental factors that strongly reduce canopy photosynthesis likely reduce fruit sucrose accumulation and result in melons of low quality.

\section{Literature Cited.}

Bianco, V.V. and H.K. Pratt. 1977. Compositional changes in muskmelons during development and in response to ethylene treatment. J. Amer. Soc. Hort. Sci. 102:127-133.

Hubbard, N. L., S.C. Huber, and D.M. Pharr. 1989. Sucrose phosphate synthase and acid invertase as determinants of sucrose concentration in developing muskmelon (Cucumis melo L.) fruit. Plant Physiol. 91:1527-1534.

Hulme, A.C. and M.J.C. Rhodes. 1971. Pome fruits, p. 333-373. In: A.C. Hulme (cd.). The biochemistry of fruits and their products. vol. 2. Academic, New York.

Lester, G.E. and J.R. Dunlap. 1985. Physiological changes during development and ripening of 'Perlita' muskmelon fruits. Scientia Hort. 26:323-331.

Lingle, S.E. and J.R. Dunlap. 1987. Sucrose metabolism in netted muskmelon fruit during development. Plant Physiol. 84:386-389.

McCollum, T. G., D.J. Cantliffe, and H.S. Paris. 1987. Flowering, fruit set, and fruit development in birdsnest-type muskmelons. J. Amer. Soc. Hort. Sci. 112:161-164.

McCollum, T. G., D.J. Huber, and D.J. Cantliffe. 1988. Soluble sugar accumulation and activity of related enzymes during muskmelon fruit development. J. Amer. Soc. Hort. Sci. 113:399-403.

Palmer, J.K. 1971. The banana, p. 65-105. In: A.C. Hulme (cd.). The biochemistry of fruits and their products. vol. 2. Academic, New York.

Pratt, H.K. 1971. Melons, p. 207-232. In: A.C. Hulme (cd.). The biochemistry of fruits and their products. vol. 2. Academic, New York.

Schaffer, A. A., B.A. Aloni, and E. Fogelman. 1987. Sucrose metabolism and accumulation in developing fruit of Cucumis. Phytochemistry 26: $1883-1887$.

Welles, G. W.H. and K. Buitelaar. 1988. Factors affecting soluble solids content of muskmelon (Cucumis melo L.) Netherlands J. Agr. Sci. 36:239-246.

Whiting, G.C. 1970. Sugars, p. 1-31. In: A.C. Hulme (cd.). The biochemistry of fruits and their products. vol. 1. Academic, New York.

Zimmerman, M.H. and H. Ziegler. 1975. List of sugars and sugar alcohols in sieve tube exudates. Encyclopedia of plant physiology (new series). vol. 1. Springer-Verlag, Berlin. p. 480-503. 